\title{
HOSPITALIDADE: INCLUSÃO DE PROFISSIONAIS COM DEFICIÊNCIA NA HOTELARIA
}

HOSPITALITY: INCLUSION OF PEOPLE WITH DISABILITIES IN THE HOTEL INDUSTRY HOSPITALIDAD: LA INCLUSIÓN DE PROFESIONALES CON DISCAPACIDAD EN LA HOTELERÍA

Sueli Marinato Abreu Cardoso

Graduada em Hotelaria pela Universidade Federal Fluminense

Niterói, Rio de Janeiro, Brasil suelimarinato@gmail.com

\section{Carolina Lescura de Carvalho Castro}

Universidade Federal Fluminense

Docente no Departamento de Turismo da Universidade Federal Fluminense Doutora em Administração pela Universidade Federal de Lavras Niterói, Rio de Janeiro, Brasil carolescura@gmail.com

\section{Caroline Araújo de Carvalho}

Graduada em Hotelaria pela Universidade Federal Fluminense

Niterói, Rio de Janeiro, Brasil caroline.araujo.carvalho@gmail.com

Data de Submissão: 22/10/2015

Data de Aprovação: 24/05/2016

RESUMO: Este artigo tem como objetivo investigar, em um empreendimento hoteleiro, a existência de práticas da hospitalidade que podem ser consideradas ações de inclusão das PCD no ambiente de trabalho. Foi realizada uma pesquisa exploratória e qualitativa, no mês de abril de 2015, em um hotel localizado na cidade do Rio de Janeiro, sendo esta delimitada ao setor de gestão de pessoas e aos 
funcionários com deficiência. A análise das entrevistas e da observação permitiu a emergência de três categorias: a inserção exclusiva, as fragilidades do departamento de gestão de pessoas e a discriminação velada. Conclui-se, portanto, que a empresa pratica mais a inserção do que propriamente a inclusão dos profissionais com deficiência. Além disso, verifica-se que a organização ainda precisa evoluir no que tange à prática da hospitalidade, pois são notáveis práticas discriminatórias e preconceituosas, além da pouca compreensão de que as pessoas com deficiência possuem um grande potencial, capaz de contribuir significantemente para o sucesso organizacional.

PALAVRAS-CHAVE: inclusão, hospitalidade, pessoas com deficiência (PcD).

ABSTRACT: This paper investigates the existence of hospitality practices at a hotel business, which can be considered actions of inclusion of people with disabilities in the work environment. An exploratory, qualitative survey was carried out in April 2015, at a hotel in the city of Rio de Janeiro, Brazil. This survey focused primarily on the hotel's Human Resources sector and its disabled employees. Analysis of the interviews led to the identification of three categories: exclusive insertion, weaknesses of the Human Resources department, and subtle discrimination. It was concluded that the company practices insertion more than the actual inclusion of the employees with disabilities. It is also clear that the company still needs to improve its hospitality practices, because the prejudices are clear, even if subtle. It also lacks the understanding that people with disabilities have great potential, and can make a significant contribution to the success of the business.

KEYWORDS: inclusion, hospitality, disabled people.

RESUMEN: Este artículo tiene como objetivo investigar en un emprendimiento hotelero la existencia de prácticas de hospitalidad que puedan ser consideradas acciones de inclusión de las PcD en el ambiente de trabajo. En el mes de abril de 2015 se realizó un estudio exploratorio y cualitativo en un hotel ubicado en la ciudad de Rio de Janeiro, delimitado al sector de gestión de personas y a los empleados con discapacidad. El análisis de las entrevistas y de la observación permitió la emergencia de tres categorías: la inserción exclusiva, las fragilidades del departamento de gestión de personas y la discriminación velada. Se concluyó, por tanto, que la empresa practica más la inserción que propiamente la inclusión de los profesionales con discapacidad. Además, se verificó que la organización todavía necesita evolucionar en lo que se refiere a la práctica de la hospitalidad, pues son notables las prácticas discriminatorias y prejuiciosas, además de la poca comprensión de que las personas con discapacidad poseen una gran potencialidad, capaz de contribuir significantemente al éxito organizacional.

PALABRAS CLAVE: Inclusión; Hospitalidad; Personas con discapacidad (PcD).

\section{INTRODUÇÃO}

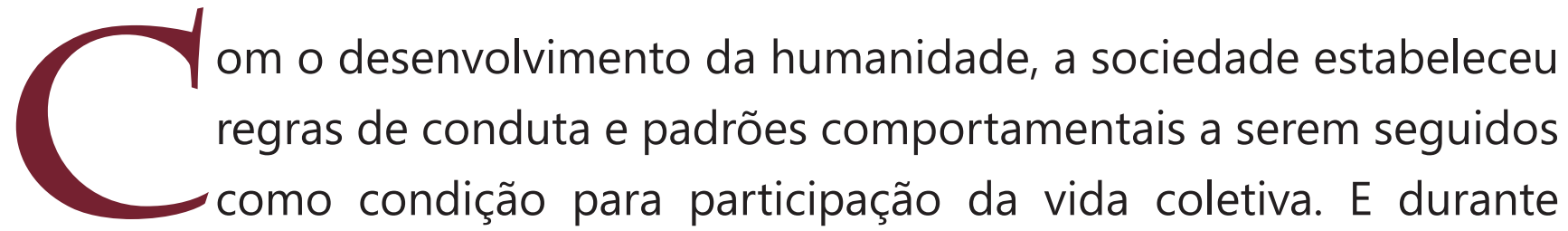
muitos séculos, as pessoas que não se enquadravam nestes padrões sociais, eram, de certa forma, excluídas do convívio social (Sassaki, 2003). 
De modo geral, a sociedade apresenta dificuldade em conviver e aceitar como iguais aqueles que apresentam vivências e comportamentos diferentes, sejam culturais, de gênero, de orientações sexuais, com deficiências físicas e/ou mentais. Por isso, todos os considerados "diferentes" conviveram, por muito tempo, com a indiferença e a invisibilidade social, política e econômica (Costa, 2004).

Atualmente, o tema diversidade tem sido discutido em diversos espaços, tendo em vista a necessidade de construir relações de convívio com diferentes pessoas, respeitando suas limitações e diferenças. Especialmente nas organizações, este assunto tem ganhado importante foco, visto que o simples fato de empregar funcionários "diferentes" pode ser considerado uma atitude de responsabilidade social empresarial (Neto \& Froes, 1999).

Assim, há uma tentativa de se diversificar a mão de obra, empregando negros, mulheres, indivíduos de origens étnicas e culturais variadas e também pessoas com algum tipo de deficiência física ou mental. Neste contexto, destaca-se o grupo de pessoas com deficiência, que tem o seu direito de inserção no mercado de trabalho garantido por lei.

Sendo assim, o presente artigo tem como objetivo geral investigar, em um empreendimento hoteleiro, a existência de práticas da hospitalidade que podem ser consideradas como ações de inclusão das PcD no ambiente de trabalho.

Entende-se que, dependendo da maneira como esses profissionais são recebidos e tratados no ambiente organizacional, essas ações podem ser consideradas práticas de hospitalidade comercial, que é compreendida na literatura como a prática da hospitalidade no ambiente organizacional (Abreu, 2003). Ou seja, a hospitalidade comercial no campo hoteleiro é designada a ação de bem receber o hóspede, atentando para a sua segurança e satisfação. Contudo, denomina-se comercial por envolver uma transação econômica, uma vez que o consumidor paga pelo serviço. Ampliando o conceito para todo o espaço organizacional, entende-se que tal hospitalidade deveria ser aplicada não apenas na relação funcionário-hóspede, mas também na relação empresa-funcionário. Para Kobayashi (2008), se os colaboradores são tratados com cordialidade e respeito, certamente reproduzirão este 
comportamento com os clientes que vierem a se hospedar no hotel. Relacionando com os profissionais que possuem alguma deficiência, acredita-se que a hospitalidade é fundamental no processo de receber e socializar essas pessoas no ambiente empresarial.

No que tange o campo científico, vale destacar que as pesquisas sobre a inserção de PcD nas organizações são incipientes. Sendo assim, é importante que haja estudos mais aprofundados sobre esse tema que contribuam com a consolidação científica deste campo em questão (Moreira, Onuma, Borges, Miranda, \& Cappelle, 2009). Mais escassas ainda são as pesquisas que buscam o diálogo entre a hospitalidade comercial e a inserção de profissionais com deficiência nas organizações.

Para desenvolver o presente artigo, optou-se por adotar o método qualitativo. A investigação foi possível por meio da aplicação de entrevistas semiestruturadas com os gestores da área de recursos humanos do hotel e com os profissionais com deficiência. Além disso, foi realizada uma observação assistemática do empreendimento, tomando nota das informações, por meio de um diário de campo. Finalmente, os dados foram analisados qualitativamente, gerando categorias de análise.

Assim, o presente artigo foi estruturado em quatro partes, além desta introdução. A primeira seção disserta sobre a hospitalidade, dando um enfoque especial à hospitalidade comercial. A segunda seção destina-se a tratar da gestão da diversidade nas organizações, destacando a inserção de PcD nas empresas. Mais adiante, na terceira parte do trabalho, são explanados os procedimentos metodológicos, bem como a análise dos dados coletados. Finalmente, a quarta e última parte é direcionada às considerações finais do artigo.

\section{A HOSPITALIDADE NO SETOR HOTELEIRO}

De acordo com Camargo (2005, p. 52), a hospitalidade é definida como "[...] ato humano exercido em contexto privado, público e comercial, de recepcionar, hospedar, alimentar e entreter pessoas temporariamente deslocadas de seu habitat natural." 
Os campos de estudo da hospitalidade, segundo este autor, são: o doméstico, o público, o comercial e o virtual. Dentre estes campos, a hospitalidade estudada será a comercial, que segundo Camargo (2005) é aquela praticada pelos prestadores de serviço nos setores hoteleiros e de restauração. Contudo, o autor questiona se esta forma de hospitalidade é praticada no seu sentido mais puro, genuíno, uma vez que envolve uma transação econômica, ou seja, o cliente paga para ser "bem recebido".

Lashley (2004) afirma que a hospitalidade está fundamentada na construção de um relacionamento entre anfitrião e hóspede e afirma que a hospitalidade comercial é a área de estudo que mais gera divergências entre autores, como Mauss (1974), Camargo (2005), Darke e Gurney (2004), Caillé (2002), Goffman (1959) e outros.

Darke e Gurney (2004) discutem sobre as ideias de Goffman em sua obra The Presentation of Selfie in Everyday Life, de 1959, a respeito da hospitalidade comercial ser considerada, por este autor, uma "encenação teatral". Para Darke e Gurney (2004), esta proposta se demonstra um tanto quanto frágil, dado que a hospitalidade doméstica poderia também ser considerada uma encenação, mesmo não ocorrendo uma transação econômica entre os envolvidos.

Os autores mencionados expõem que a hospitalidade doméstica pode ser uma encenação, considerando que, no intuito de receber bem o hóspede, o hospedeiro prepara o ambiente, a refeição e a bebida de maneira diferente da habitual, de modo a impressionar o convidado. Com isso, consideram que a concepção de Goffman (1959) sobre a hospitalidade encenada, cujo ambiente é visto como um cenário teatral, é frágil porque, como citado anteriormente, a mesma situação pode ocorrer no espaço doméstico.

Caillé (2002, p.142) propõe que a dádiva se trata de "[...] toda prestação de serviços ou de bens efetuada sem garantia ou retribuição, com o intuito de criar, manter ou reconstituir o vínculo social", assim como os autores Belchior e Poyares (1987, p. 16) definem que a hospitalidade pode ser praticada como "a prestação, gratuita ou não, de serviços obtidos normalmente por uma pessoa em seu próprio lar, mas que, por não possuí-lo ou por estar dele ausente, temporariamente, não os tem à sua disposição". 
De acordo com a afirmação dos autores citados, a hospitalidade pode ser feita mediante pagamento ou não, ou seja, a ideia de hospitalidade comercial fica explicitada neste fragmento de texto.

Camargo (2005, p. 45) demonstra sua opinião sobre a hospitalidade comercial afirmando:

[...] a hospitalidade sempre foi atributo de pessoas e de espaços, não de empresas; a observação deve, pois, dirigir-se para o que acontece além da troca combinada, além do valor monetizável de um serviço prestado, para o que as pessoas e os espaços proporcionam além do contrato estabelecido.

Camargo (2005) reforça a ideia de que é possível manter práticas de hospitalidade no ambiente comercial, desde que os prestadores de serviços estejam dispostos a ofertar, além de alojamento, alimentos e bebidas, no caso do setor hoteleiro, atenção, solidariedade, cordialidade e dedicação dispensadas ao cliente, que não fica estabelecido no contrato de compra de serviços.

Lashley (2004) faz reflexões sobre a hospitalidade comercial que pode ser calculista, ou seja, visar apenas o lucro, ou pode se alinhar à hospitalidade doméstica, desde que haja um treinamento dos prestadores de serviço, baseado nos princípios de bem-estar, segurança e satisfação do hóspede.

A hospitalidade comercial abrange não só as relações entre cliente e prestador de serviço, mas também a inter-relação entre os clientes internos (funcionários) e clientes externos (hóspedes).

Considerando que a hospitalidade exercida no setor hoteleiro é vista como um instrumento de diferenciação e eficiência na qualidade dos serviços, entende-se, portanto, que esta deveria ser uma prática oferecida tanto para os hóspedes, como para os funcionários. Se os colaboradores se sentem acolhidos, se são tratados com cordialidade e respeito, certamente reproduzirão este comportamento com os clientes que vierem a se hospedar no hotel (Kobayashi, 2008).

Desta forma, a hospitalidade poderia ser trabalhada no primeiro momento com os gestores e sequencialmente com os demais funcionários, fazendo com que esta prática faça parte da cultura organizacional da empresa (Pirolo \& Torres, 2012). 
Segundo Guerrier e Adib (2004), os trabalhadores do setor hoteleiro têm dificuldade de criar vínculos de amizade fora de seu local de trabalho, tendo em vista que sua jornada de trabalho é diferente de outros setores de serviço. Isto torna as relações entre os funcionários ainda mais importantes, pois neste espaço é que serão construídos os relacionamentos de amizade. "As empresas que satisfizerem seus clientes internos serão as com maior chance de terem clientes também satisfeitos" (Bekin, 2004, p. 140).

Para reforçar o pensamento dos autores citados, vale destacar o seguinte conceito de hospitalidade segundo Baptista (2002, p. 157), "modo privilegiado de encontro interpessoal marcado pela atitude de acolhimento em relação ao outro". A autora entende que:

[...] a hospitalidade remete para a necessidade de dar respostas às interpelações incômodas daqueles que falam de exclusão. Não se pode esquecer que para muitas pessoas, o mundo continua a ser um lugar terrivelmente hostil. Também por isso é importante promover as condições de vida que nos permitem fazer do mundo uma casa para todos os seres humanos, sem exclusões (Baptista, 2002, p. 163).

Ainda conforme Baptista (2002), há muita hostilidade nas relações sociais que induzem à exclusão das minorias. No entanto, a hospitalidade vai de encontro a esse modo de vida com uma proposta de integração considerando o mundo como um lugar para todos.

A autora Dencker (2003) acrescenta que a hospitalidade pode ser uma forma de inclusão das populações que são excluídas e que buscam viver em um mundo mais solidário e justo. Reforçando assim o pensamento de que a hospitalidade pode ser entendida como saber conviver com as diferenças dentro de parâmetros de respeito, tolerância e reciprocidade.

Souza (2005) também relata que a hospitalidade no ambiente comercial depende de como as pessoas envolvidas na relação se comportam. E, para que este espaço seja mais hospitaleiro, é necessário o uso de técnicas ou práticas da área de gestão de pessoas, que garantam uma convivência harmoniosa no ambiente laboral. 


\section{A GESTÃO DA DIVERSIDADE - A INSERÇÃO DE PCD NO MERCADO \\ DE TRABALHO}

O departamento de Gestão de Pessoas tem como função gerenciar e orientar o comportamento das pessoas dentro das empresas, além de realizar os processos de recrutar, selecionar, treinar, avaliar o desempenho, motivar e recompensar os funcionários, de modo a promover melhor qualidade de vida dos mesmos (Maximiano, 2007).

Quando se fala em gerir o comportamento humano, Xavier (2006) considera que as pessoas são diferentes umas das outras, seja por seu modo de pensar, por sua crença religiosa, orientação sexual, política, estilo de vida, gênero, etnia, cultura, etc. Sendo assim, o departamento de gestão de pessoas deve gerir a diversidade que, de acordo com Fleury (2000), pode ser conceituada como:

[...] um mix de pessoas com identidades diferentes interagindo no mesmo sistema social. Nesses sistemas, coexistem grupos de maioria e de minoria. Os grupos de maioria são os grupos cujos membros historicamente obtiveram vantagens em termos de recursos econômicos e de poder em relação aos outros (Fleury, 2000, p. 20).

Para esclarecer, os grupos denominados de minoritários não são representados, necessariamente, por menos pessoas. Para Moreira et al. (2009), as "minorias" são constituídas por grupos que possuem traços culturais ou físicos específicos, que são desvalorizados e não inseridos na cultura da maioria (grupo majoritário), o que gera um processo de exclusão e discriminação.

Acredita-se que a gestão da diversidade é capaz de promover a criatividade, a inovação, a troca de experiências (Aoun \& Gibeily 2007; Aranha, Zambaldi, \& Francisco, 2006), além de reduzir as desigualdades, permitindo a inclusão e a melhoria da qualidade de vida de muitos empregados.

O presente trabalho tem como foco estudar, especificamente, a inserção e a inclusão de PcD no mercado de trabalho vistas, conforme foi esclarecido, como minoria nos ambientes organizacionais. Desse modo, é importante compreender a trajetória desses indivíduos que conquistaram de forma gradual o direito à inserção no mercado de trabalho. 
Até a década de 1970 as PcDs eram excluídas do convívio social (Aranha, 2003). Era uma época em que vigorava o modelo médico da deficiência, que consistia em considerar que as PCD eram incapazes de desenvolver qualquer atividade produtiva. Estavam isentas de qualquer dever de cidadania e eram tratadas simplesmente como pessoas doentes, tendo apenas o direito ao tratamento médico, como prevê o artigo 7 da Declaração dos Direitos das Pessoas Deficientes de 1975 (Sassaki, 2003).

No artigo 7, são assegurados os direitos das pessoas deficientes, assim denominadas na época, ao tratamento médico, psicológico e funcional, entendendo que esta ação possibilitaria o desenvolvimento de suas capacidades (Sassaki, 2003). Neste modelo, havia um protecionismo às PcD que acabavam sendo excluídas do mercado de trabalho, pois se compreendia que a própria inserção seria uma maneira de exploração.

Desta forma, as PcD eram impelidas a se segregarem em clínicasespecializadas, afastadas de seus familiares, com o intuito de receberem tratamento para que fossem "curadas". Portanto, entendia-se que a deficiência era uma doença que deveria ser tratada para que o sujeito pudesse fazer parte do convívio social.

De acordo com Sassaki (1997), ao analisar o artigo $7^{\circ}$ da Declaração dos Direitos das Pessoas Deficientes, a busca por integração devia partir das PcD. Sendo assim, a sociedade mantinha uma atitude de resistência em aceitar e incluir em seu seio esta diversidade, já que toda a responsabilidade de inclusão era transferida para as pessoas com deficiência.

Mais adiante, surgiu o modelo de integração social, que tinha como ideal integrar as PcD nos sistemas sociais comuns a toda a sociedade, como educação, trabalho, família e lazer, já que o modelo médico da deficiência serviu para excluir os mesmos do convívio social (Sassaki, 2003).

Este modelo, portanto, serviria para extirpar a prática da exclusão social a qual PCD foram submetidas por muito tempo. E, como forma de integração, na década de 1970, houve um aumento da oferta de instituições especializadas ao atendimento de $\mathrm{PcD}$, como as escolas especiais, os centros de reabilitação, as associações desportivas, etc. (Sassaki, 2003). 
A ideia original do modelo integracionalista, que era de incorporar as PcD a uma convivência em sociedade, usufruindo dos mesmos direitos e oportunidades, foi deturpada porque a sociedade não estava preparada para integrar estas pessoas. Assim, foi criado o conceito de normalização, que consistia em normalizar os serviços e os ambientes de modo a oferecer condições de vida às $P C D$, semelhantes ao restante da sociedade, ou seja, as PcD deveriam ter comportamentos padronizados como normais pela sociedade (Amaral, 1994).

O modelo de integração foi intensificado no final de 1980, com os movimentos de luta pelos direitos das PCD, formados pelas comunidades acadêmicas, instituições sociais e vanguardeiras de PcD. O propósito desses movimentos era divulgar que a prática da integração social não resultava no fim da discriminação e nem promovia uma igualdade de oportunidades que satisfizesse plenamente os direitos de todas as pessoas com deficiência (Sassaki, 2003).

Um movimento que marcou esta década de 1980 foi o Ano Internacional da Pessoa Deficiente, declarado pela Organização das Nações Unidas (ONU), quando as PcD passaram a se organizar e lutar por suas causas (Figueira, 2008).

Alguns anos depois, a Constituição Federal Brasileira de 1988 estabelece as ações que iriam promover o bem-estar e a integração das pessoas portadoras de deficiência ${ }^{1}$. Um ano depois é criada a Lei n. ${ }^{\circ}$ 7.853, que estabelece que o poder público deve garantir às pessoas com deficiência o pleno exercício de seus direitos básicos, como direito à educação, à saúde, ao trabalho, ao lazer e à previdência social, propiciando o seu bem-estar pessoal, social e econômico.

Dentre as ações de integração ficaram previstas a reserva de cargos no setor público para as $\mathrm{PcD}$, a prestação de assistência social para habilitação e reabilitação, a criação de programas de prevenção, a capacitação e o atendimento especializado para as PcD física, sensorial ou mental, a criação de normas na construção das obras públicas e a fabricação de veículos coletivos, se necessário, adaptações, a fim de assegurar a acessibilidade das PcD.

1 "Portador de deficiência" era o termo usado nesta década e que, atualmente, não é mais considerado apropriado, pois a palavra "portador", segundo o dicionário, se refere a alguém que conduz ou carrega algo, portanto, poderia deixar de carregar no momento que Ihe conviesse. 
Não se deve considerar que o modelo integracionalista foi inútil, pois ele deu início à inserção das $\mathrm{PcD}$, a pelo menos ocuparem ou dividirem o mesmo espaço que a classe majoritária, tornando-se visíveis. Se outrora, com a segregação, a sociedade não percebia essas pessoas, agora não poderiam "fingir" que elas não existiam. As PcD estavam inseridas na sociedade e, com isso, seria necessário criar políticas que promovessem sua inclusão social.

É importante conceituar os termos inserção e inclusão para que haja um entendimento de sua diferenciação. Segundo Carvalho-Freitas e Marques (2010), inserção pode ser entendida como um ato de introduzir PcD em ambientes de trabalho para que desenvolvam atividades profissionais com os demais funcionários.

O termo inclusão social começou a ser usado a partir de 1990, baseado no modelo social da deficiência, e parte do pressuposto de que a sociedade deve se preparar e se adaptar para receber esses sujeitos, incluindo-os, portanto, nos sistemas sociais comuns. Como declara Sassaki (2003), o processo de inclusão é uma via de mão dupla, dado que tanto as minorias como a sociedade geral devem se posicionar.

Nesteparadigma de inclusão social o governo federal teve um papelsignificativo, criando, por exemplo, a Lei $n^{\circ} 8213 / 91$, conhecida como "Lei de Cotas", em que as empresas com mais de 100 (cem) funcionários têm como obrigatoriedade contratar um percentual de $\mathrm{PCD}$, sendo este percentual proporcional ao número de empregados, como demonstrado no Art. 93: de 100 a 200 empregados (2\%), de 201 a 500 (3\%), de 501 a 1.000 (4\%) e de 1.001 em diante (5\%).

A ação do governo não se limita à criação de leis, mas também fiscaliza o cumprimento das mesmas por meio do Ministério do Trabalho e Emprego (MTE) e se houver irregularidade, a empresa pode ser multada e um relatório é encaminhado para o Ministério Público do Trabalho (MPT), que produz um "termo de ajuste de conduta", em que é estipulado um prazo para que a empresa se regularize (BRASIL, 2015).

Ainda que o governo fiscalize as empresas na questão da inserção de PcD, isto não garante que haja nas organizações ações que promovam a inclusão. De acordo com Sassaki (2003), uma organização inclusiva é aquela que: 
[...] acredita no valor da diversidade humana, contempla as diferenças individuais, efetua mudanças fundamentais nas práticas administrativas, implementa adaptações no espaço físico, adapta procedimentos e instrumentos de trabalho, treina todos os recursos humanos na questão da inclusão, etc. (Sassaki, 2003, p. 65).

É relevante que as empresas participem deste processo de inserção e também da inclusão das PcD, seja por motivos de obrigatoriedade, de responsabilidade social, ou para obter uma vantagem competitiva diante de seus concorrentes. É necessário haver uma coalizão entre políticas públicas e as empresas que fomentem ações inclusivistas para que essas pessoas tenham o direito ao trabalho, que é garantido por lei.

Ainda que as empresas cumpram as exigências legislativas, não é possível afirmar que seus funcionários com deficiência estejam efetivamente incluídos. A inclusão envolve o não preconceito e a aceitação das diferenças. Irigaray e Saraiva (2009) relatam, com base em seus estudos, que o preconceito é um óbice para se desenvolver as políticas de estímulo à diversidade. É o que ocorre quando os próprios ocupantes dos cargos de chefia estão eivados de preconceito e não propiciam um ambiente organizacional acolhedor para os funcionários com deficiência.

Sassaki (2005) complementa esse pensamento e denomina acessibilidade como a ausência de barreiras que promove a inclusão. Podem-se, a partir da concepção do autor, citar algumas dessas barreiras:

a) barreira atitudinal ou falta de acessibilidade atitudinal, é a ausência de práticas e programas de sensibilização e conscientização dos indivíduos, de uma forma geral, que reflita na convivência de uma sociedade diversificada.

b) barreira arquitetônica, pode ser compreendida como toda estrutura física que não possibilita uma PcD transitar em um determinado espaço.

c) barreira comunicacional, seria qualquer impedimento, seja pela falta de conhecimento, por exemplo, de língua de sinais, ou inexistência de instrumentos que possibilitem a comunicação escrita, como os textos em braile, ou seja, o que impede a pessoa com deficiência de se comunicar interpessoalmente. 
d) barreira metodológica refere-se aos métodos e às técnicas de estudo que são utilizados, mas que não são adequados para as $\mathrm{PcD}$, tornando o uso dos mesmos ineficiente para a obtenção de resultados satisfatórios.

e) barreira instrumental abrange todo tipo de equipamento ou instrumento que possa dificultar ou impedir que a PCD desenvolva atividades diárias.

f) barreira programática é aquela que não é visível, porém está embutida nas políticas públicas ou nas normas da empresa e que impossibilita a inclusão social.

Para que de fato a sociedade assuma uma postura inclusivista, seria necessário a queda dessas barreiras, de modo a garantir que qualquer pessoa com deficiência tenha seus direitos assegurados como todo cidadão.

\section{PROCEDIMENTOS METODOLÓGICOS}

O presente estudo é qualitativo e de natureza exploratória que, segundo Gil (2007), tem como objetivo proporcionar a familiarização com o problema da pesquisa, tornando-o mais explícito.

Foi realizada uma pesquisa de campo com o intuito de coletar informações que permitissem compreender e desvendar melhor o objeto de estudo. Em campo, utilizou-se como instrumentos de coleta de dados a entrevista semiestruturada e a observação assistemática.

Foram criados dois roteiros norteadores, um destinado às entrevistas para os cargos gerenciais e outro para os funcionários com deficiência. O roteiro que foi aplicado para os gerentes foi constituído de 22 questões, sendo divididas em dois blocos. No primeiro bloco estão as informações pessoais do entrevistado e no segundo, as informações sobre a empresa e a forma de trabalho do departamento de Gestão de Pessoas.

O segundo roteiro, destinado aos colaboradores com deficiência, foi construído por 3 blocos de perguntas, totalizando 35 questões. O primeiro bloco consiste nas informações pessoais do entrevistado, no segundo sua 
trajetória pessoal e profissional e, no terceiro bloco, sua trajetória no emprego atual e as relações interpessoais desenvolvidas no local de trabalho.

$\mathrm{Na}$ observação assistemática, não havia um roteiro norteador, as observações foram feitas e anotadas antes, durante ou depois das entrevistas. Algumas informações foram obtidas por meio de conversas com alguns profissionais da portaria.

A pesquisa foi realizada em uma rede hoteleira brasileira com três unidades na cidade do Rio de Janeiro, sendo duas destas unidades objeto de estudo deste artigo. A rede foi fundada no século $X X$, possui e administra outras unidades em várias regiões do Brasil. É importante esclarecer que as duas unidades investigadas não foram escolhidas aleatoriamente. Entre as três opções, somente duas possuíam em seu quadro de funcionários profissionais com algum tipo de deficiência, além de terem se demonstrado disponíveis para a realização da pesquisa. Outros empreendimentos, além dos pertencentes à rede pesquisada, também foram contatados, contudo nenhum demonstrou interesse e abertura para conceder as entrevistas, talvez por se tratar de um assunto delicado e que ainda possui muita resistência em termos de discussão.

Para dar início à análise, optou-se por caracterizar os entrevistados, criando assim o Quadro 1, que contém a identificação dos participantes e, para preservar suas identidades, foram criados codinomes.

Quadro 1- Características dos participantes

\begin{tabular}{|c|c|c|c|c|}
\hline Nome e Idade & Escolaridade & Cargo & $\begin{array}{l}\text { Tempo de } \\
\text { empresa }\end{array}$ & Tipo de deficiência \\
\hline $\begin{array}{l}\text { Tânia } \\
57 \text { anos }\end{array}$ & Superior em Psicologia & $\begin{array}{c}\text { Gerente de } \\
\text { Desenvolvimento }\end{array}$ & 7 anos & - \\
\hline $\begin{array}{l}\text { Fernando } \\
37 \text { anos }\end{array}$ & Superior em Psicologia & $\begin{array}{l}\text { Coordenador de } \\
\text { recrutamento e seleção }\end{array}$ & 4 anos & - \\
\hline $\begin{array}{l}\text { Renato } \\
35 \text { anos }\end{array}$ & $\begin{array}{l}\text { Superior em desenho } \\
\text { industrial }\end{array}$ & $\begin{array}{c}\text { Auxiliar de } \\
\text { Departamento Pessoal }\end{array}$ & 9 anos & Auditiva \\
\hline $\begin{array}{l}\text { Laura } \\
42 \text { anos }\end{array}$ & Ensino Médio & Ajudante de cozinha & 1 ano & $\begin{array}{c}\text { Atrofia muscular } \\
\text { tibial }\end{array}$ \\
\hline $\begin{array}{l}\text { Márcia } \\
34 \text { anos }\end{array}$ & Ensino Médio & $\begin{array}{c}\text { Auxiliar de } \\
\text { Departamento Pessoal }\end{array}$ & 9 anos & Auditiva \\
\hline $\begin{array}{l}\text { Leandro } \\
23 \text { anos }\end{array}$ & $\begin{array}{l}5^{\circ} \text { Ano do Ensino } \\
\text { Fundamental }\end{array}$ & $\begin{array}{l}\text { Auxiliar Operacional } \\
\text { de Reciclagem }\end{array}$ & 2 anos & Síndrome de Down \\
\hline
\end{tabular}

Fonte: Elaboração própria 
Após a coleta, as entrevistas foram transcritas e os dados foram submetidos a uma análise qualitativa, da qual emergiram quatro categorias de análise: inserção exclusiva, fragilidade do departamento de gestão de pessoas e a discriminação velada.

\section{ANÁLISE E INTERPRETAÇÃO DOS RESULTADOS}

De acordo com a leitura e a análise das transcrições das entrevistas, foram extraídas algumas falas dos entrevistados, de modo a possibilitar a leitura da fala sem interferência do pesquisador.

\section{INSERÇÃO EXCLUSIVA}

Nesta categoria foi observada que a inserção das pessoas com deficiência realizada pela empresa é "exclusiva". O uso deste termo tem o sentido de excludente, pois muitos profissionais são excluídos em razão do seu tipo de deficiência, dado que a empresa não está devidamente preparada para receber funcionários com qualquer tipo de limitação, seja ela física ou mental.

Começando pelo processo de recrutamento e seleção, um dos gestores entrevistados comenta que, para contratar uma pessoa com deficiência, é necessário que o cargo seja compatível com as limitações do contratado.

Primeiramente a gente identifica quais são os cargos que podem ser ocupados por pessoas com deficiência. Porque dependendo da limitação que a pessoa tenha, ela não pode ocupar qualquer cargo, por exemplo, hoje nós temos uma estrutura física que é difícil manter um cadeirante fazendo parte da empresa (Fernando).

No primeiro momento, o entrevistado tem um olhar só para as limitações que impedem o profissional com deficiência de assumir um cargo, sendo que o principal seria conhecer as habilidades e as competências que este sujeito possui, para então, analisar se ele preencheria as exigências do posto a ser ocupado. No final da fala, o coordenador de recrutamento e seleção ressalta que o hotel não tem estrutura para agregar profissionais cadeirantes, o que 
demonstra uma atitude excludente e de falta de acessibilidade, denominada por Sassaki (2003) de barreiras arquitetônicas.

Foi observado que a entrada de serviço do hotel é feita por dois lances íngremes de escadas, e sondando os profissionais da segurança sobre ser este o único acesso, eles confirmaram. Esta informação vai contra a declaração do entrevistado, que diz ser difícil manter um cadeirante, o que na verdade seria impossível, dada as condições físicas do empreendimento.

Esta falta de estrutura para atender aos profissionais com deficiência é reforçada por outro entrevistado que ocupa cargo de gerência:

Embora aqui tenha elevador, tem muitos corredores onde seria difícil um cadeirante circular. Teria que abrir todos os corredores para que eles possam se locomover, isto não existe. Existe buscar no mercado deficientes que possam estar atuando sem precisar fazer grandes adequações. A empresa não se preocupa tanto com esse detalhe ainda. Não chegou ainda a esse grau de sofisticação" (Tânia).

Fica explícito que a gestão não faz e nem tem intenção de fazer uma adequação física para receber de forma abrangente os profissionais com deficiência. A entrevistada afirma que a empresa ainda não alcançou tal nível de "sofisticação". A acessibilidade nada mais é do que uma forma de permitir a inclusão deste profissional, não tendo relação alguma com a empresa ser mais ou menos sofisticada em suas práticas.

Esta descrição remete ao modelo integracionalista que consistia no indivíduo com deficiência se adequar à sociedade e às condições de trabalho existentes (Bahia; Schommer, 2009; Sassaki, 2003).

Além da falta de estrutura arquitetônica, a empresa não fornece recurso instrumental para os funcionários com deficiência, como é possível observar no relato do colaborador com deficiência auditiva:

Eu não atendo o telefone, o aparelho auditivo atrapalha porque encosta no telefone. Eu tenho um amigo que trabalha na sala comigo e ele me ajuda, anota o recado no papel. Eu trabalho aqui no subsolo, na verdade aqui não tem sinal de celular para mandar mensagem pelo Whatsapp, então o funcionário me ajuda a pegar informação (Renato). 
O entrevistado narra uma situação em que a falta do sinal de internet no seu local de trabalho dificulta o desenvolvimento de suas funções que, dentre outras, é a de se comunicar com outros departamentos. Na visão de Sassaki (2003), isto poderia ser entendido como uma barreira comunicacional. É evidente que tal dificuldade poderia ser resolvida sem precisar utilizar grandes recursos financeiros e o profissional poderia desempenhar de forma mais independente suas funções.

Há outro relato em que é afirmada a restrição em contratar cadeirantes e pessoas com perda total da visão:

Hoje a gente não tem uma estrutura para adequar o layout para receber esse cadeirante. Mas em relação aos outros tipos de deficiência, temos auditivo, o visual de baixa acuidade e o monocular. Hoje não temos um visual total, porque não temos estrutura para recebê-los (Fernando).

O entrevistado declara que há pessoas com diferentes tipos de deficiência fazendo parte do quadro de funcionários da empresa. No entanto, ele afirma que tem um funcionário com deficiência visual de baixa acuidade, que é a perda da visão periférica e das cores, e é um tipo de deficiência que não requer da empresa uma implementação instrumental para que o indivíduo possa trabalhar, ou seja, a empresa não tem uma preocupação de se adequar para receber pessoas com essas deficiências.

O departamento de gestão de pessoas também deixa bastante claro que inserir PcD requer uma dedicação que dispende muito tempo dos líderes de cada setor e que, muitas vezes, há uma resistência destes em aceitar uma PcD na sua equipe de trabalho. Desta forma, é passada uma postura de que o departamento em questão não trabalha com políticas de inclusão com suas lideranças, mostrando, com isso, uma fragilização organizacional.

\section{FRAGILIDADE DO DEPARTAMENTO DE GESTÃO DE PESSOAS}

Após a transcrição das entrevistas, foi possível detectar, por meio dos relatos, algumas atitudes de gestão de pessoas que não são apropriadas para promover 
a inclusão. Por isso, esta categoria tem como objetivo mostrar as fragilidades deste setor empresarial.

Alguns dos problemas percebidos são a ausência de um processo seletivo bem estruturado e a falta de treinamento específico destinado às pessoas com deficiência para desenvolverem suas funções e se relacionarem com os demais funcionários. Tal fato pode ser verificado na fala a seguir:

O hotel me ligou, aí eu vim ver, fazer entrevista, então eu comecei assim, logo no primeiro dia. Eu nem esperava que fosse naquele momento que eu ia começar, aí eu tive que ligar pra minha mãe e avisar que eu ia demorar um pouco porque ia começar no mesmo dia (Márcia).

Esta contratação repentina, em que o hotel faz um processo seletivo e, no momento da entrevista já contrata o candidato, sem fazer antes uma análise mais apurada, sugere que havia urgência em empregar um profissional com deficiência.

Um processo seletivo mal estruturado pode contrair para a empresa uma pessoa que não esteja alinhada com as metas e com a cultura organizacional, dificultando o alcance dos objetivos traçados. Por isso, é necessário escolher as melhores técnicas para avaliar o candidato, sendo a entrevista uma das centrais e mais usadas, já que possibilita ao entrevistador conhecer o comportamento do entrevistado (Zaccarelli; Teixeira, 2008).

A entrevista, sendo bem executada, pode obter um bom resultado, mas há casos em que isso não ocorre. Como este fato narrado pelo gestor:

O Ricardo já não fala, ele ouve. Não sei se ele usa aparelho auditivo. Eu converso com ele muito pouco, é mais gestual mesmo, mas a gente não entra no mérito da conversa em LIBRA. Eu mesmo tenho um linguajar de LIBRAS muito básico. Mas o Ricardo é uma pessoa que se comunica, ele faz leitura labial. Muitas vezes a dificuldade é nossa, ditos "normais", interpretar de uma forma errônea (Fernando).

O desconhecimento por parte do gestor sobre o grau de dificuldade que o funcionário apresenta é notório. A falta desta informação inviabiliza a alocação de forma adequada deste profissional, podendo acarretar um desempenho insatisfatório na função em que exerce. O gestor acrescenta que é possível 
haver comunicação mesmo quando não faz uso da linguagem de sinais, o que levanta dúvidas se as entrevistas realizadas realmente propiciam uma avaliação justa dos candidatos, já que há uma barreira comunicacional entre os participantes. A troca de informação e a troca de experiência, além da socialização, são práticas de hospitalidade, como menciona Claude Raffestin (1997 apud Grinover, 2002).

A inexistência destes elementos pode sinalizar uma fragilidade do setor de gestão de pessoas, assim como a falta de sensibilização das lideranças para lidar com as limitações das pessoas com deficiência.

Porque as pessoas não sabem, saber sabem, mas não entendem que eu preciso falar um pouco mais alto porque eu uso aparelho e, às vezes, eu falando baixo eu não entendo o que eu falo. Então, por isso, às vezes, eu forço um pouquinho, aí dá a impressão de que estou gritando, que eu tô falando alto com a pessoa. Então isso é difícil deles entenderem, agora só quem trabalha comigo sabe. Ela (a chefe) já tentou explicar em algumas reuniões que, às vezes, eu sou assim, que eu não sou ruim, que eu não estou distratando as pessoas (Márcia).

Este relato, em que a respondente descreve uma falta de compreensão por parte dos colaboradores sobre a sua necessidade de falar alto para se ouvir, demonstra que não há um programa de sensibilização com o intuito de preparar as pessoas para lidar com as diferenças e limitações que os profissionais com deficiência possam apresentar. Ainda nesta fala, a entrevistada comenta que a sua chefe tentou explicar para os demais funcionários o porquê de ela falar alto. Entretanto, o método usado talvez não tenha sido apropriado, pois a chefe não conseguiu se fazer entender.

Há uma barreira metodológica (Sassaki, 2003), ou seja, existe uma ineficácia em sensibilizar os colaboradores e também a liderança no sentido de gerir a diversidade que, de acordo com as autoras Hanashiro e Carvalho (2005), é saber lidar com grupos de pessoas com menos representatividade no contexto social.

Quando Tânia foi questionada se havia um treinamento para as PCD desempenharem suas funções, ela afirmou que todos os colaboradores, independente de terem deficiência, passaram por um programa de ambientação que consistia em: 
Na primeira semana ele é orientado por um colaborador que é mais antigo, ou pela própria liderança, dependendo do setor onde ele vai ser inserido. A liderança ou o colaborador mais antigo da área passa essa ambientação, que é mostrar todas as tarefas, todas as responsabilidades, apresentar o tipo de trabalho que ele vai desenvolver e ficar acompanhando (Tânia).

Segundo Tânia, os funcionários iniciantes recebem orientação, realizada pela liderança ou por um profissional mais antigo, para que desenvolvam suas tarefas diariamente. Porém, segundo o relato do Leandro, que descreve seu primeiro dia de trabalho no hotel, esta prática nem sempre acontece.

Foi difícil. Tinha muito trabalho. Eu fiz tudo sozinho. Aprendi sozinho (Leandro).

A repetição da palavra "sozinho" serve para realçar que o novo funcionário não teve auxílio de outra pessoa para orientar o passo a passo da função que desempenharia na organização.

Ao perguntar sobre a existência de treinamento específico para capacitar as chefias no trato com os funcionários com deficiência, a resposta obtida foi a seguinte:

Já tiveram palestras, logo no início do programa de implantação para deficientes, hoje nem tanto. [...] Existe um trabalho que é feito internamente de apoio pra eles. Mas eu confesso que esse é um ponto de deficiência que os Hotéis $X$ têm, e que eu acho que a maioria das empresas têm, que é fazer com que as lideranças entendam o processo de acolher um deficiente (Tânia).

No início da implantação do programa, a empresa investiu em palestras de sensibilização. No entanto, como descrito no relato anterior, não houve oferta sistemática de capacitação continuada. Isto se reflete nas atitudes dos atuais líderes da empresa. Também é declarada a dificuldade dos líderes em acolher as $P C D$, e esta frase pode ser mais bem entendida a partir da leitura do relato a seguir, no qual a respondente afirma que as PcD são menos produtivas.

Se você tem um profissional que produz $100 \%$ e o outro que produz $80 \%$, é óbvio que eu vou optar pelo de $100 \%$, porque é o meu setor que está em jogo, é a produtividade do setor (Tânia). 
Tânia, ao explicar que existem trabalhadores $100 \%$ e $80 \%$ produtivos, faz relação com as pessoas que não possuem e aquelas que possuem algum tipo de deficiência, respectivamente. Ela ainda enfatiza que a pressão pela alta produtividade leva os gestores a criarem uma certa resistência para receber a PcD. Isto demonstra o quanto a empresa é despreparada neste sentido, pois apresenta uma visão completamente equivocada de que estes profissionais atrapalharão o desempenho da equipe.

A falta de conhecimento sobre a potencialidade do trabalho realizado por pessoas com deficiência e a crença de que esses trabalhadores não têm condições de acompanhar o ritmo de produtividade que é imposto pelas empresas, por causa da competitividade mercadológica acabam por causar conflitos na liderança, os quais não aceitam absorver esta mão de obra (Tanaka \& Manzini, 2005).

Um fator curioso da declaração anterior é que Tânia afirma de forma categórica que as pessoas com deficiência são menos produtivas, mesmo sem ter um processo que garanta uma avaliação de desempenho destes funcionários.

Não existe uma avaliação de desempenho estruturada. Hoje nós temos a avaliação inicial, que é a avaliação no período de experiência (Fernando).

Os gestores afirmam que não têm um método de avaliar o profissional com deficiência, porém determinam que estes produzem menos que os demais, criando, portanto, uma postura preconceituosa em relação às PCD. A falta de conhecimento das chefias sobre a capacidade que as PcD têm pode gerar discriminação, já que são obrigadas a conviver e a coordenar as atividades desses profissionais sem acreditar no seu potencial de trabalho.

\section{DISCRIMINAÇÃO VELADA}

Esta categoria foi criada porque durante a leitura das entrevistas surgiram alguns relatos dos líderes e de alguns funcionários sobre a ocorrência de discriminação no local de trabalho. A palavra discriminação nem sempre foi usada de forma explícita, sendo substituída pelo termo "brincadeiras", como mostra a fala a seguir: 


\begin{abstract}
Discriminação em si, eu acho que não. Existe as brincadeiras que eu mesmo já acompanhei, a própria pessoa com deficiência acaba cedendo a essas brincadeiras, como vou dar um exemplo que eu vi um dia desses...nós temos uma mesa de totó na sala de jogos e o deficiente falou, "o ceguinho aqui vai detonar vocês," então, ele mesmo, na tentativa de fazer parte do grupo, se deixa levar pela brincadeira (Fernando).
\end{abstract}

O gestor começa a fala negando que há discriminação no hotel. Ele relata que existem "brincadeiras" e que a pessoa com deficiência acaba se sujeitando a elas como forma de ser aceito pelo grupo. Não fica perceptível que o gestor veja esta situação como algo que possa incomodar a pessoa com deficiência, e que seja uma atitude preconceituosa, discriminatória e nada hospitaleira.

Diferentemente, a funcionária Márcia interpreta de forma mais crítica uma situação semelhante:

Porque quem realmente não tem o meu problema, não entende às vezes porque eu falo alto. E às vezes, certas brincadeiras por causa da minha deficiência, faz com que eu me sinta ofendida (Márcia).

De acordo com Márcia, os colaboradores não entendem a sua deficiência e, por isso, fazem certas "brincadeiras" que ela considera ofensivas. No entanto, a visão do gestor é diferente, pois ele acredita que essas "brincadeiras" são bem aceitas pelos funcionários que têm deficiência, não percebendo que estas atitudes causam desconforto, discriminam e agridem as pessoas.

Dando continuidade, a gerente Tânia reforça o que foi afirmado por Fernando, quando diz que na empresa não existem práticas discriminatórias:

Não existe discriminação interna, [...] já existe um acolhimento natural. A gente nunca viu nenhuma discriminação, nenhum colaborador que tenha deficiência veio aqui pra reclamar que foi maltratado pelo colega. Muito pelo contrário, eles são ajudados, eles são apoiados, são super acolhidos, por ser já algo trabalhado neles desde o início do processo de inclusão dos deficientes (Tânia).

A gestora afirma não ter presenciado atos discriminatórios, exaltando que os trabalhadores com deficiência nunca prestaram queixa ao departamento de gestão de pessoas neste sentido. Contudo, vale lembrar que na categoria anterior, "Fragilidade do departamento de gestão de pessoas", a mesma 
gerente produz um discurso completamente discriminatório ao afirmar que os trabalhadores sem deficiência são $100 \%$ produtivos, enquanto aqueles que possuem alguma limitação são $80 \%$ produtivos. Além disso, ela havia revelado que há uma resistência dos líderes na aceitação de tais profissionais, pois estes comprometeriam o desempenho do setor. Reforçando esta postura discriminatória, ela ainda relata:

\begin{abstract}
Mas tem deficientes que têm problemas mesmo, tem o aspecto cognitivo comprometido, eles não vão produzir da mesma forma, não vão compreender da mesma forma. Eles são problemáticos, geralmente eles têm problemas no relacionamento interpessoal, então exige do líder da equipe todo um cuidado especial, uma compreensão. Isso vai dispender mais tempo desse profissional, que dispenderia com outro (Tânia).
\end{abstract}

A entrevistada tem uma concepção de que algumas $\mathrm{PcD}$ são problemáticas e de difícil relacionamento, como se somente as PCD tivessem problemas de relacionamento interpessoal, sendo isto inerente a elas. Esta compreensão distorcida pode ser denominada de barreira atitudinal, que Sassaki (2003) descreve como atitudes de caráter discriminatório que impedem a inclusão das PcD.

Vale destacar que a discriminação é uma atitude não só presente entre as pessoas que não possuem deficiência. Muitas vezes, a própria PcD acaba reproduzindo este tipo de comportamento, como é possível verificar na fala seguinte:

\begin{abstract}
Não tem preconceito, eles falam que eu nem pareço $\mathrm{PNE}^{2}$, porque não aparece, só se eu vestir uma bermudinha ou um vestido, porque assim de calça não dá pra ver. Às vezes eles falam, "ué, você é PNE?," ficam me olhando de cima embaixo, "o que que você tem?" Aí eu explico pra eles que eu nasci com a perna machucada. Aí eles ficam admirados, porque não dá pra ver. Nunca senti preconceito, graças a Deus (Laura).
\end{abstract}

Nesta narrativa, Laura, que tem uma deficiência quase imperceptível, conta que os colaboradores sem deficiência ficam admirados pelo fato de ela não 2 A sigla significa Pessoa com Necessidades Especiais. Esta denominação foi modificada porque, segundo Carvalho-Freitas e Marques (2007), não especifica as pessoas com deficiência. A expressão abrange qualquer pessoa que tenha uma limitação temporária como, por exemplo, as pessoas obesas, os idosos que tenham dificuldade de locomoção, etc. 
ISSN: 1983-7151

apresentar características de uma PCD e isto é visto com bons olhos por ambas as partes. Se, por um lado, os colegas de profissão se sentem mais confortáveis em não ter que lidar com as diferenças, por outro, a PcD se sente melhor acolhida. Vale destacar que a entrevistada nega, inclusive, a própria limitação, uma vez que prefere dizer que nasceu com a "perna machucada" e não atrofiada, o que explicaria melhor a sua deficiência.

Dando continuidade à discussão de existirem ou não práticas discriminatórias na organização, outra funcionária relata como se sentiu ao ingressar no Hotel:

[...] a primeira pessoa que eu tive contato aqui no trabalho eu senti que ela teve um pouquinho de preconceito. Mas eu também não encarei isso como algo muito sério, como um empecilho para eu ficar na empresa, porque eu sei que, em qualquer lugar, a gente vai passar por isso, então por isso até hoje eu estou aqui. Eu consigo lidar com essas coisas (Márcia).

De acordo com a declaração da Márcia, pode-se perceber que sua recepção não foi hospitaleira, pois já se sentiu discriminada ainda na fase de ambientação com o local de trabalho. Ela completa dizendo que não levou a sério o comportamento da pessoa que a recepcionou, manifestando que este tipo de atitude é comum, e que para ser aceita e permanecer no trabalho é necessário saber lidar com essas situações.

Esta situação pode ser caracterizada como discriminação, mas que, pela necessidade de manter o vínculo empregatício, é suprimida. Este fato reflete bem o que Sassaki (2003) aborda sobre a inclusão, pois as PCD têm que se posicionar contra os atos discriminatórios, não devendo se conformar e acreditar que é um caso perdido, que não vale a pena lutar para serem respeitadas.

\section{CONSIDERAÇÕES FINAIS}

O objetivo deste estudo foi averiguar a existência da hospitalidade na inclusão de PcD em uma empresa hoteleira. Este objetivo foi alcançado por meio de uma pesquisa teórica, que serviu para obter um aprofundamento do tema a ser abordado, o que fomentou a construção de um roteiro de entrevista que granjeou dados que possibilitaram atingir o resultado. 
Por meio da pesquisa de campo, foram coletados relatos de funcionários de uma organização, dos quais emergiram três categorias de análise: inserção exclusiva, fragilidade do departamento de gestão de pessoas e discriminação velada, que possibilitaram responder à questão problema deste artigo, sobre a existência da prática da hospitalidade em relação aos funcionários que possuem deficiência no hotel investigado.

Foi possível identificar que o hotel insere a PcD sem promover uma inclusão social destes indivíduos, já que seleciona de forma excludente pessoas com determinados tipos de deficiência que não exijam da empresa grandes adequações, como físicas e de comunicação.

A empresa também tem uma concepção de que as PcD são produtivamente inferiores aos demais funcionários, tendo assim uma postura preconceituosa e de desvalorização desta força de trabalho, o que se reflete na resistência dos líderes em receber no seu setor esse profissional com deficiência.

Portanto, a empresa não gera meios de ampliar a integração desses indivíduos com a prática da hospitalidade, que pode ser manifestada por meio de palavras e gestos, ancorada no carinho e na sensibilidade de entender o próximo, como afirma Baptista (2002).

A ausência do exercício da hospitalidade impossibilita que a empresa seja considerada inclusiva, que, de acordo com Sassaki (2003), é a que valoriza a diversidade, considera as diferenças de cada indivíduo, faz adaptações no espaço físico e implementa instrumentos de trabalho e procedimentos, além de realizar treinamentos de sensibilização a todas as pessoas, para que promovam a inclusão por meio de atitudes hospitaleiras.

Uma das dificuldades para a realização deste trabalho foi conseguir o contato do departamento de gestão de pessoas da empresa para iniciar um diálogo que resultasse na permissão da realização das entrevistas. E mesmo de posse dos contatos de e-mail e telefone, foi necessário manter certa insistência para atenderem às solicitações requeridas. Outra dificuldade foi encontrar autores como Dencker (2003) e Baptista (2002) que fazem uma relação da hospitalidade como forma de inclusão social. 
Pode-se destacar que este artigo contribuiu para esclarecer que, mesmo depois de 24 anos da promulgação da Lei de Cotas, existem empresas que permanecem com uma postura de resistência e de discriminação em relação à inclusão das PcD no mercado de trabalho, e que será necessário desenvolver outras políticas públicas para que as empresas sejam motivadas a promover a inclusão.

Sendo, portanto, necessário realizar mais pesquisas sobre a inserção de PcD nas organizações, de maneira a ampliar o conhecimento das causas que levam as empresas hoteleiras a terem uma postura pouco ativa em relação à inclusão dessas pessoas. E a partir dos resultados de futuras indagações, seja possível implementar políticas inclusivas mais eficientes.

\section{REFERÊNCIAS}

Abreu, V. A. (2003). A máquina da hospitalidade. In: DENCKER, A. F. M; BUENO, M. S. (orgs.) Hospitalidade: cenários e oportunidades. São Paulo: Pioneira Thomson Learning, 29-48.

Amaral, L. A. (1994. Pensar a diferença: deficiência. Brasília: CORDE.

Aoun, G., \& Gibeily, T. (2015). Managing diversity in the workplace. Université Saint-Joseph, 2007. Recuperado em 7 outubro, de http://www.fgm.usj.edu.lb/pdf/a52007.pdf.

Aranha, F., Zambaldi, F., \& Francisco, E. (2006) Diversity Management and Performance: A Review of Evidence and Findings in Academic Papers from 1973 to 2003. 26th International Congress of Applied Psychology. Atenas. CD-ROM.

Aranha, M. S. F. (2003). Trabalho e Emprego: Instrumento de construção da Identidade pessoal e Social. São Paulo: SORRI-BRASIL; Brasília: CORDE.

Bahia. M. S., \& Schommer P. C. (2009). Inserção profissional com pessoas com deficiência: Aprendendo com as práticas cotidianas de uma experiência empresarial. In: Encontro Nacional de Pós-graduação em Administração. São Paulo: Anais... XXXIII EnANPAD.

Baptista, I. (2002). Lugares de hospitalidade. In: DIAS. C. M. M. (orgs.). Hospitalidade: Reflexões e perspectivas. Barueri, SP: Manole, 157-164.

Bekin, S. F. (2004). Endomarking: como praticá-lo com sucesso. São Paulo: Prentice Hall.

Belchior, E. O., \& Poyares, R. (1987) Pioneiros da hotelaria no Rio de Janeiro. Rio de Janeiro: Senac. 
Brasil. (2015). LEI No 8.213, DE 24 DE JULHO DE 1991. Recuperado em 21 abril, de http:// www.planalto.gov.br/ccivil_03/leis/l8213cons.htm.

Brasil. (2015). MINISTÉRIO DO TRABALHO E EMPREGO. Recuperado em 29 março, http:// portal.mte.gov.br/data/files/FF8080812CCDAEDE012CD0A2B79F70B3/inclusao_pessoas_ defi12_07.pdf.

Brasil. (2015). MINISTÉRIO DO TRABALHO E EMPREGO. Recuperado em 03 junho, http:// portal.mte.gov.br/fisca_trab/13-2-qual-o-papel-do-ministerio-publico-do-trabalho.htm.

Caillé, A. (2002). Antropologia do dom. Petrópolis: Vozes.

Camargo, L. O. (2005). Hospitalidade. $2^{\circ}$ ed. São Paulo: Aleph.

Carvalho-Freitas, M. N. C., \& Marques, A. L. (2007). A diversidade através da história: a inserção no trabalho de pessoas com deficiência. Revista Organizações \& Sociedade, 14(41), abr-jun.

Carvalho-Freitas, M. N. C., \& Marques, A. L. (2010). Inserção de pessoas com deficiência em organizações brasileiras: um estudo com empresas socialmente responsáveis. Revista Gestão. Org, 8(3), 483-502, set.-dez.

Costa, F. B. (2004). Homens invisíveis: retratos de uma humilhação social. São Paulo: Globo.

Darke, J., \& Gurney, C. (2004). Como alojar? Gênero, hospitalidade e performance. In: LASHLEY, C. e MORRISON, A. Em busca da hospitalidade: perspectivas para um mundo globalizado. Barueri, SP: Manole, 111-143.

Dencker, A. F. M. (2003). Considerações finais. In: DENCKER, A. F. M; BUENO, M. S. (orgs.) Hospitalidade: cenários e oportunidades. São Paulo: Pioneira Thomson Learning, 145-146.

Dicionário Aurélio. (2015). Recuperado em 18 abril, de http://dicionariodoaurelio. com/portador.

Figueira, E. (2008). Caminhando no silêncio: uma introdução à trajetória das pessoas com deficiência na história do Brasil. São Paulo: Giz Editora.

Fleury, M. T. L. (2000). Gerenciando a diversidade cultural: experiências de empresas brasileiras. Revista de Administração de Empresas. São Paulo, 40(3), 18-25, jul.-set.

Gil, A. C. (2007). Gestão de Pessoas: Enfoque nos Papéis Profissionais. São Paulo: Atlas.

Grinover, L. (2002). Hospitalidade: um tema a ser reestudado e pesquisado. In: DIAS, C. M. M. (orgs.). Hospitalidade: Reflexões e perspectivas. Barueri, SP: Manole, 25-38. 
Guerrier, Y., \& Adib, A. (2004). O trabalho na indústria da hospitalidade. In: LASHLEY C.; MORRISON, A. (Orgs.). Em busca da hospitalidade: perspectivas para um mundo globalizado. Barueri: Manole, 357-386.

Hanashiro. D. M. M., \& Carvalho, S. G. (2005). Diversidade cultural: panorama atual e reflexões para a realidade brasileira. Revista Eletrônica de Administração, ed. 47, 11(5), set.- out.

Irigaray, H. A. R., \& Saraiva, L. A. S. (2009). Políticas de diversidade nas organizações: uma questão de discurso? Revista de Administração de Empresas, 49(3), jul.- set..

Kobayashi, T.M. T. (2008). Endomarketing como ferramenta para a implantação da hospitalidade na hotelaria. Revista Acadêmica Observatório de Inovação do Turismo, 3(4), Dez..

Lashley, C. (2004). Para um entendimento teórico. In LASHLEY, C.; MORRISON, A. (orgs.). Em busca da hospitalidade: perspectivas para um mundo globalizado. Barueri, SP: Manole, 1-24.

Mauss, M. (1974). Sociologia e Antropologia. São Paulo: EPU/Edusp.

Maximiano, A. C. A. (2007). Introdução à administração (7a.ed). São Paulo: Atlas.

Moreira, L. B., Onuma, F. M. S., Borges, C. L. P., Miranda, A. R. A., \& Cappelle, M. C. A. (2009). O trabalho para os portadores de necessidades especiais: um caminhar pela diversidade através dos conceitos de poder, minoria e deficiência. In: Encontro de gestão de pessoas e relações de trabalho. Curitiba: Anais...IIEnGPR.

Neto, F. P. M., \& Froes, C. (1999) Responsabilidade social e cidadania empresarial: a administração do terceiro setor. Rio de Janeiro: Qualitymark.

Pirolo, M. C. F., \& Torres, R. G. (2012). Hospitalidade na Hotelaria de São Paulo (Brasil): a percepção de camareiras cooperadas. Turismo \& Sociedade. Curitiba, 5(2), 507-526.

Sassaki, R. K. (1997). Inclusão da pessoa com deficiência no mercado de trabalho. São Paulo: PRODEF.

Sassaki, R. K. (2003). Inclusão: Construindo uma sociedade para todos (5a ed). Rio de Janeiro: WVA.

Sassaki, R. K. (2005). Inclusão: O paradigma do século XXI. Revista da Educação Especial. Out. 2005, 19-23. Recuperado de http://portal.mec.gov.br/seesp/arquivos/pdf/ revistainclusao1.pdf

Souza, C. A. (2005). Responsabilidade social empresarial: uma forma contemporânea de hospitalidade comercial em resorts - estudo de caso da pousada do Rio Quente Resorts. Dissertação de mestrado, 110f. São Paulo: Universidade Anhembi Morumbi. 
Tanaka, E. D. O., \& Manzini, E. J. (2005). O que os empregadores pensam sobre o trabalho da pessoa com deficiência? Revista brasileira de educação especial, 11(2), mai.- ago. 2005, 273-294.

Xavier, R. A. P. (2006). Gestão de pessoas na prática. São Paulo: Gente.

Zaccarelli, L. M., \& Teixeira, M. L. M. (2008). Um lado da moeda: atraindo e selecionando pessoas. In: Hanashiro, D., \& Teixeira, M. L. (orgs.). Gestão do fator humano: uma visão baseada em stakeholders. (2a ed). São Paulo: Saraiva, 2008, p. 115-149. 